\title{
Opinión pública y transformación del espacio público en América Latina: del Informe MacBride a la Red Indymedia
}

\author{
Francisco de Jesús Aceves González* \\ Universidad de GuAdalajara
}

En 1980, a lo largo de diez páginas, los autores del Informe MacBride esbozaron una aproximación conceptual sobre la "opinión pública" y realizaron un diagnóstico sobre algunas de las características que presentaba este fenómeno a escala mundial.

El propósito del presente trabajo es analizar, a la luz de las transformaciones en el espacio público experimentadas en Latinoamérica, los avances que desde la publicación del Informe se han evidenciado tanto en la discusión teórica como en la investigación empírica de la opinión pública, y que en nuestro concepto, establecen modificaciones sustanciales al diagnóstico del referido Informe.

In 1980, across ten pages, the authors of the MacBride Report sketched a conceptual approximation about public opinion and offer an overview of some of the characteristics of this phenomenon at a global scale.

The purpose of the present paper is to analyze, the transformations in the public space in Latin America and the progress that since the publication of the said Report, has been made in the theory as well as the empirical investigation of the public opinion. In our opinion, substantial changes have occurred both in the conception of public opinion as well as in the ways it is now being studied in the social Latin American context.

* Miembro del Sistema Nacional de Investigadores (SNI). Doctor en Ciencias Sociales. Adscrito al Departamento de Estudios de la Comunicación de la Universidad de Guadalajara. Integrante del Cuerpo Académico "Globalización, espacio público e identidad". Miembro de las asociaciones de investigadores IAMCR, WAPOR, ALACIP, ALAIC Y AMIC. 


\section{INTRODUCCIÓN}

Hace 30 años, en el marco de la 19a Reunión de la Conferencia General de la UNESCO realizada en Nairobi en 1976, su entonces presidente Amadou-Majhtar M'Bow constituyó la Comisión Internacional para el Estudio de los Problemas de la Comunicación, conformada por 16 miembros de igual número de países y presidida por Sean MacBride, quienes a lo largo de cuatro años realizaron un "examen general de los problemas relativos a la comunicación de la sociedad contemporánea, a la luz de los progresos tecnológicos y de la evolución creciente de las relaciones mundiales en toda su complejidad y amplitud"(MacBride, 1980 , p. 9) y cuyas conclusiones fueron publicadas en 1980 en un documento que ha sido conocido como el Informe MacBride. En ese momento, las relaciones internacionales se caracterizaban por un profundo desequilibrio entre el desarrollo alcanzado por un puñado de países avanzados y los países que conformaban el extenso y abigarrado mapa geográfico del llamado "tercer mundo". Esta asimetría se evidenciaba en las definiciones que intentaban ilustrar el carácter de dicha relación. Así, las palabras subdesarrollo, dependencia, explotación, hasta la sutil denominación de países "en vías de desarrollo", se asociaban indefectiblemente al perfil de los países tercermundistas, entre los cuales se encontraban los latinoamericanos.

Sensibles a este contexto, los 16 miembros de la Comisión, entre ellos el colombiano Gabriel García Márquez y el chileno Juan Somavía, enfocaron su análisis en los desequilibrios observados en el campo de la comunicación y la información. En su extenso y documentado estudio que abarcó los principales aspectos que conforman el fenómeno comunicacional, el Informe dedicó un capítulo -10 páginas- dirigido a realizar un diagnóstico del estado en que se encontraba el fenómeno de lo público y la opinión pública a escala mundial.

A casi tres décadas de su publicación, resulta pertinente, en el contexto de las transformaciones en el espacio público experimentadas en América Latina, revisar críticamente tanto los supuestos teóricos, sobre los cuales los expertos fundamentaron su estudio, como las condiciones materiales que caracterizaban el desarrollo de la opinión pública en ese tiempo. El propósito que anima este trabajo es discutir sobre la vigencia de las conclusiones a las que arribaron los miembros de la Comisión, respecto al fenómeno de la opinión pública.

En la primera parte se aborda lo relativo a la conceptualización teórica de la opinión pública expresada en el documento y su análisis crítico a la luz del debate contemporáneo del estudio en torno a la opinión pública. En la segunda 
parte se intenta una aproximación a las transformaciones del espacio público experimentadas en América Latina en las dos últimas décadas y su impacto en la conformación del fenómeno de la opinión pública contemporánea.

\section{OPINIÓN PÚBLICA: DE LA INTERACCIÓN DIALÓGICA}

A LA COMUNICACIÓN MEDIÁTICA

En su primer apartado, intitulado "El concepto de Público", los autores advierten de las numerosas definiciones asociadas al concepto de opinión pública, producto de "las diferencias ideológicas y sociales existentes en un mundo muy diversificado". En efecto, Childs en un estudio publicado en 1965 había reportado 48 diferentes registros sobre su significado (Price, 1994). Diversidad no solamente originada, por cierto, por "las diferencias ideológicas y sociales existentes" sino mas bien por las diversas perspectivas disciplinarias desde las que se abordaba el fenómeno. En 1968, Davison apuntaba que los especialistas en opinión pública coincidían en definirla como la "suma de opiniones individuales sobre una cuestión de interés público" y agregaba que dichas opiniones podrían "ejercer cierta influencia sobre el comportamiento de un individuo, de un grupo o de un gobierno" (Davison, 1968).

En contraste a esta definición los expertos del informe señalaban que la coincidencia entre las definiciones radicaba en que no se podía considerar al público como "la suma amorfa de los individuos que lo componen", por lo que no se podría hablar de "publico sino de públicos". Y proponían la siguiente definición.

La opinión pública no es solamente la suma de las opiniones individuales, sino mas bien un proceso continúo de comparación y de contraste de opiniones basadas en una amplia gama de conocimientos y de experiencias (MacBride, 1980, p. 337).

Si bien su anotación crítica a la visión de un público conformado por una masa amorfa y su pronunciamiento sobre la existencia de una diversidad de públicos era muy pertinente, también resultaba evidente su apreciación sobre el carácter restrictivo de la definición propuesta por Davison. A la consideración de la opinión pública como suma de opiniones individuales adicionaban, aunque en forma no muy precisa, una dimensión dinámica - proceso continuo- como elemento constitutivo del fenómeno de la opinión pública y una cualidad deliberativa en tanto "contraste de opiniones" sustentadas por una "amplia gama de conocimientos y experiencias". 
De hecho, ambas características habían sido ya, desde 1962, específicamente enunciadas por Jürgen Habermas en su obra clásica sobre la transformación estructural de la vida pública, convertida en piedra de toque en el debate contemporáneo sobre la opinión pública. En dicho escrito, después de exponer la crisis conceptual derivada de las definiciones otorgadas al fenómeno que desembocan en considerarlo ya como "ficción institucionalizada del estado de derecho", ya en su "disolución socio-psicológica", Habermas planteaba que:

"Un concepto de opinión pública con sentido histórico, normativamente suficiente para las pretensiones del Estado social, teoréticamente claro y empíricamente ponderable, solo puede conseguirse partiendo del cambio estructural de la publicidad misma y de la dimensión de su desarrollo" (Habermas, 1981, p. 269).

Es en ese proceso, en el que se realiza una publicística políticamente activa, constituido por dos ámbitos comunicacionales de relevancia política: el de las opiniones informales, no públicas, y el conformado por las opiniones institucionalmente autorizadas, o formales, interconectados ambos por la mediatización de los medios de comunicación de masas, que a juicio de Habermas puede existir "una opinión pública en sentido estricto", es decir que "los dos ámbitos comunicativos sean mediados por el ámbito de la notoriedad pública crítica". Mediación que implica la participación de las personas privadas en los procesos de comunicación formal en el seno de las organizaciones.

Por otra parte, la aproximación al concepto de "público" establecido por los autores del informe, se encontraba sustentado, aunque no en forma explícita, en los hallazgos derivados de la Mass Communication Research: el paradigma de los efectos limitados y la exposición selectiva a los medios (Katz y Lazarsfeld, 1979). Sin embargo, aunque reconocían que la interacción entre los medios y el público es "un elemento esencial en el funcionamiento de la comunicación" ante el tema de la influencia o de los efectos de los medios, adoptaron una posición poco definida. En efecto, con respecto al impacto de los medios, los expertos se deslizan del papel de la influencia personal derivada del contexto de los usuarios de los medios, a la teoría de la sociedad de masas (Wright Mills, 1978), caracterizada por la conformación de una audiencia atomizada cuya expresión más clásica sería difundida por David Riesman en su libro de La Muchedumbre Solitaria.

Habría que señalar que en la concepción habermasiana, la noción de opinión pública se encuentra indisolublemente ligada a una concepción de proceso comunicacional eminentemente dialógica, que privilegia la interacción cara a cara por 
sobre las formas de comunicación mediáticas. Entre otros autores que han criticado esta posición, Thompson (1996) alerta hacia el aferramiento a una concepción esencialmente dialógica del espacio público (publicness) ${ }^{1}$ que interpreta la irrupción de la comunicación mediática como una fatalidad. Por el contrario, el autor sostiene que la mayor centralidad de los medios ha posibilitado el surgimiento de un nuevo espacio público (publicness) sustancialmente diferente al establecido por el modelo tradicional.

Con el desarrollo de los nuevos medios de comunicación -empezando con la imprenta, pero incluyendo las formas más recientes de comunicación electrónica- el fenómeno de la propiedad pública [publicnnes] se ha desvinculado progresivamente de la idea de una conversación dialógica en cierto lugar compartido. Se ha convertido en des-espacializada y no-dialógica, y de manera creciente más vinculada al tipo de visibilidad distintiva producida por y a través de los media (especialmente de la televisión). (Thompson, 1998, p. 177).

Por otra parte, desde una perspectiva "sistémica", Luhmann resignifica la noción de opinión pública, a la cual habría que considerarla ya, "no como dominio (racional) del dominio (político) sino como principio de selección de la decisión (comunicación) política" (Aguilar Villanueva, 1987, p. 115).

...la opinión pública -afirma Luhmann- no puede dominar y ni siquiera sustituir al detentador del poder. No le puede prescribir el modo con el cual él debe ejercer el poder. Su relación con el ejercicio del poder no es una relación de causa y efecto, sino de estructura y proceso, Su función no consiste en afirmar la voluntad -la voluntad popular, esa ficción del pensamiento causal elemental- sino en el dar orden a las operaciones de selección (Luhmann citado por Aguilar Villanueva, 1987, p. 115).

La importancia de la opinión pública, no reside, entonces, en buscar el consenso entre las opiniones sino principalmente en el establecimiento de "temas" capaces de suscitar la "atención" pública. Lo que sigue entonces es un proceso de comunicación política, que como todo proceso comunicacional presupone además de un lenguaje común, otros dos aspectos: "la elección de un tema y la articulación de las opiniones relativas al tema". El tema constituye la "es-

${ }^{1}$ Tanto publicness, como antiguamente publicity, podrían traducirse algo así como "vida social pública", como la esfera comunicativamente estructurada de lo público.

Opinión pública y transformación del espacio público en América Latina: • 331 del informe MacBride a la red Indymedia 
tructura" de la comunicación política, y por tanto condiciona el intercambio de opiniones.

Por otra parte, el establecimiento de temas cumple una doble función. La primera consiste en "despertar y capturar la atención política y de esta manera poner en movimiento la comunicación política"; la segunda es "desencadenar las muchas y variadas opiniones sobre lo que se debe decidir o la manera como se debe instrumentar la decisión".

Esto hace suponer -escribe Luhmann- que el sistema político, en cuanto se funda en la opinión pública, no debe ser absolutamente integrado por las reglas de decisión sino por las reglas de atención (Ibid: 122).

Esta preeminencia de las reglas de atención se explica si se considera que "la función política última de la opinión pública es la de elencar las elecciones políticas posibles". Es decir, que aunque la decisión política ya no es atributo de la opinión pública, tampoco las decisiones gubernamentales son absolutamente arbitrarias. El nexo establecido entre la sociedad política y la sociedad civil, asume la forma de un proceso de comunicación política, en la cual, los temas juegan un papel relevante.

En este proceso, los medios de comunicación de masas realizan un papel de singular relevancia. La selección de los temas, se encuentra determinada por las características técnicas y las normas de los medios. Lo opinión pública se configura en torno a ellos. Los temas seleccionados se reflejan como opinión pública, pero a su vez.

...la opinión pública actúa como un espejo, cuya superficie posterior está constituida también por un espejo. Quien da la información ve en el medio de la información corriente a sí mismo y a otras fuentes que emiten información. Quien recibe la información se ve a sí mismo, así como a otros que reciben informaciones, y aprende, poco a poco, ante qué cosas debe actuar de modo altamente selectivo para poder actuar en el contexto que, de vez en cuando, se le presenta (ya sea la política, la escuela, los grupos de amigos y los movimientos sociales). El espejo mismo es opaco (Luhmann y De Georgi, 1993, p. 433).

La concepción tradicional de la función "mediadora" de los medios, adquiere aquí una nueva dimensión. Más que un canal utilizado en forma instrumental, para la transmisión de significados entre un emisor y un receptor, los medios se 
convierten en instancia clave en el proceso de comunicación política, es decir, en el lugar donde toma cuerpo la opinión pública.

Es en este punto en donde reside, quizá, la modificación sustantiva en la concepción de la opinión pública. En su configuración y desarrollo indivisible de un espacio público caracterizado por su mediatización.

\section{LA OPINIÓN PÚBLICA NACIONAL:}

DE LA MUCHEDUMBRE SOLITARIA A LA ENCUESTOCRACIA

En su capítulo segundo "opinión pública nacional”, el Informe ofrece una serie de reflexiones sobre la situación de la opinión pública en el contexto nacional. Destaca en particular tres aspectos: el tipo de régimen político, los medios de comunicación y los métodos utilizados para conocer dicha opinión.

Con respecto al régimen político, habría que recordar que en 1980, el autoritarismo constituía el signo característico de los sistemas políticos en América Latina. En el grueso de los países campeaba el militarismo de uno u otro signo: Pinochet estrenaba constitución en Chile; Videla en Argentina, Stroessner en Paraguay, los epígonos de duvalierismo en Haití, así también Honduras, Bolivia, El Salvador, Uruguay, Brasil y Guatemala. Por su parte, alineada en el campo socialista, la dictadura castrista se perpetuaba en Cuba. En contraste solo un puñado de países contaba con gobiernos emanados por el voto popular: México, Costa Rica, Venezuela, Ecuador, Perú y Colombia. Y en Nicaragua luego de una cruenta guerra revolucionaria el Frente Sandinista de Liberación en Nicaragua dio fin a la dictadura somozista y se instaló durante la década siguiente en el poder. 25 años después, son los gobiernos democráticos los que se han convertido en el sustento de los sistemas políticos latinoamericanos, solamente Cuba padece un régimen autoritario.

En este sentido, el panorama político observado por los autores del Informe al momento de su elaboración ha sufrido una radical transformación. De hecho, este movimiento democratizador, se desarrolla en los ańos siguientes a su publicación y evidentemente, estas transformaciones han repercutido en la conformación de la opinión pública en América Latina.

Si como afirma Sartori (1992), la opinión pública es "el fundamento esencial y operativo" de la democracia, la instauración de gobiernos democráticos sentó las bases para su desenvolvimiento y consolidación. Empero el proceso de desarrollo ha sido lento y sinuoso. Las visiones contrapuestas que conciben a la opinión pública ya como expresión de la voluntad popular basada en el 
debate racional (Rosseau) ya como elección de sus representantes políticos por el individuo (Bentham y Mill) se encuentran plenamente vigentes, y establecen la diferencia entre una democracia deliberativa y la democracia refrendaria (plebiscitaria) que se mantiene todavía en el territorio de las utopías.

El segundo aspecto abordado en el informe es el relacionado con el papel de los medios de comunicación en la conformación de la opinión pública. En 1980, en consonancia con los regímenes autoritarios, los medios de comunicación funcionaban como instrumentos de control social del poder estatal. Televisa y sus noticieros en México, el diario El Mercurio en Chile simbolizaban en el espacio público latinoamericano, la supeditación del discurso informativo al discurso oficial. La represión militar y policíaca se ensañaba contra la prensa independiente.

En este aspecto también, las transformaciones operadas en el ámbito de los medios masivos han modificado profundamente el carácter de la comunicación política en el seno de la sociedad. En efecto, los medios constituyen hoy por hoy el espacio privilegiado en donde se debaten los asuntos de interés público. La mediatización de la esfera pública ha provocado la subordinación del discurso político a los formatos establecidos por la industria de los medios. La política se ha transformado en videopolítica (Sartori, 1992 y 1998), las contiendas electorales transitan por los márgenes estrechos de la mercadotecnia política. En este contexto, la noción de la prensa como "cuarto poder" que los autores del Informe utilizaron para ilustrar el papel de los medios como un "contrapoder" al gobierno y otras autoridades establecidas, ha quedado ampliamente rebasada. En palabras de Ramonet (2002), el poder mediático constituye actualmente el segundo poder, solamente atrás del económico, aunque estrechamente vinculado con él: "el poder mediático hoy combina poder económico y poder ideológico".

Empero, en forma paralelo y a veces a contrapelo, el comportamiento de los medios ha evidenciado también modificaciones positivas. De la sujeción casi absoluta al autoritarismo del Estado, los medios experimentan un proceso creciente de autonomía, De la censura y autocensura como elementos definitorios de su criterio editorial, los medios se han venido constituyendo, si bien en forma desigual y bajo la presión ciudadana, en espacios abiertos a la crítica y al debate social.

El tercer aspecto se refería a las herramientas metodológicas utilizadas para identificar y definir la existencia de la opinión pública. Para los autores, las encuestas representaban un instrumento del poder para detectar el pulso de la opinión pública, detectar sus demandas, conocer sus percepciones y en 
el marco de las contiendas políticas, el instrumento que permitía anticipar pronósticos electorales. Veían a la encuesta como el método para condensar las opiniones que albergaba una sociedad atomizada. Sus resultados eran para consumo interno de los patrocinadores, que los guardaban celosamente de la vista del público.

Ha sido Wolton (1992), en un clarificador artículo, quien ha identificado a los sondeos de opinión, como la expresión visible de la opinión publica, ubicándola como uno de los elementos que constituyen el proceso de la comunicación política en interacción con los actores políticos y los medios masivos de comunicación. Hay que indicar que este modelo conceptual dinamitó las concepciones arraigadas a una comunicación política encadenada por una comunicación unidireccional y vertical. La prensa ha dejado de ser "la voz de los sin voz", porque éstos han encontrado su propio canal de expresión en los sondeos y las encuestas.

Su poder es tal que ha logrado derribar gobiernos, determinar políticas públicas y frenar el abuso del poder frente a los derechos de los ciudadanos. Los políticos han resentido la fortaleza de esta expresión pública y alertan sobre los riesgos de caer en la "encuestocracia"

En el tercer apartado, intitulado "opinión publica mundial" los autores del Informe naufragan en la concepción de un mundo altamente departamentalizado. Para ellos, la opinión pública mundial consistía en la identificación de problemas similares en los diversos países. La opinión mundial se conformaba de cara a lo nacional. De todas las miradas del Informe, ésta ha sido la que ha experimentado las mayores transformaciones. Su visión corresponde a la visión del mundo antes de la Internet. Ante el desarrollo incontenible de los nuevos movimientos sociales, pacifistas, antinucleares, por los derechos civiles, estudiantiles, ecologistas, feministas, etc., el documento reconocía que "la opinión publica mundial está todavía en su fase inicial”, y aseguraba el desarrollo progresivo de estas formas de expresión.

Aunque por otra parte insistía en su visión apocalíptica de los medios. "Las fuentes de información son limitadas y solo se expresa un punto de vista, el público queda manipulado por la propaganda" escribieron en el más puro espíritu Orwelliano, sin embargo basta un poco de navegación por el ciberespacio para verificar la enorme diversidad de fuentes para acceder ante casi cualquier asunto a una significativa variedad de versiones. A diferencia de hace 25 años, cuando la información era férreamente controlada, ahora, en cuestiones de conocimiento, el que busca encuentra. 
A lo que asistimos hoy, en palabras de Keane (1997) es a la transformación estructural del espacio público. La configuración dinámica y sucesiva de micro, meso y microespacios públicos, derivados de la calidad y dimensión de los asuntos, acontecimientos que actúan como sus detonantes. Un levantamiento focalizado en las selvas chiapanecas, tiene repercusiones directas en el parlamento europeo, y los grupos zapatistas proliferen virtualmente por la red. INDYMEDIA distribuye globalmente las noticias que solamente circulaban por los conductos panfletarios de la "comunicación alternativa". Asistimos a la desterritorialización de las demandas, a la globalización de los movimientos, entre éstos el anti-globalización. Es decir, a la configuración del ciberespacio público.

\section{¿HACIA UNA SOCIEDAD DE LA INFORMACIÓN?}

En 1990, en un artículo escrito por el décimo aniversario del Informe, Márques de Melo documentaba la escasa relevancia que habían otorgado al documento diversos sectores sociales (intelectuales, políticos, medios) y su casi nulo impacto en el ámbito de académico y en las decisiones gubernamentales. En otras palabras, el informe MacBride no penetró a la opinión pública, no llegó a convertirse en asunto de su interés. Y aunque Marqués de Melo reconocía la vigencia de los objetivos del Informe criticaba que en lo relativo a las políticas de comunicación, en el documento "predominó una visión estatizante, en detrimento de la postura dirigida al fortalecimiento de la sociedad civil".

Empero, habría que señalar, que en lo relativo a la opinión pública, esta visión estatizante no se observa. Por el contrario, en el colofón del capítulo, bajo el rubro "mas allá de los conceptos de público y opinión pública", los autores del Informe visualizan, que la superación del desequilibrio informativo y la modificación del modelo vertical y autoritario imperante en los flujos comunicacionales, solo será posible a condición de asignar "una mayor preeminencia al concepto de participación de los ciudadanos".

A 26 años del Informe, las transformaciones en el espacio público latinoamericano a que hemos aludido, han modificado sustancialmente las condiciones en que se desarrollaban los procesos de la opinión pública. Escasas son las correspondencias, pues, entre la descripción del fenómeno realizado por los autores del documento, con las circunstancias actuales. No obstante, habría que reconocer su lúcida anticipación y su visión utópica, al convocar como un requisito indispensable, la participación ciudadana, para "fomentar la transformación de un público pasivo, sometido a fuerzas y a medios de co- 
municación social dominantes, en una verdadera comunidad... en un público que no se contente con ser espectador y testigo pasivo de las actividades ajenas" (MacBride, 1980, p. 346).

En diciembre de 2003, con la asistencia de más de 11,000 representantes de 175 países se realizó en la ciudad de Ginebra, la primera fase de la Cumbre Mundial sobre la Sociedad de la Información. Promovida por la Organización de las Naciones Unidas (ONU), la Cumbre Mundial reconocía las asignaturas pendientes del Informe MacBride en el ámbito de la información internacional. En su Declaración de la Sociedad Civil identifica las nuevas características de la asimetría informacional:

La desigual distribución de las Tecnologías de la Información y la Comunicación (TIC) y la falta de acceso a la información que tiene una gran parte de la población mundial, fenómenos que suelen denominarse brecha digital, son de hecho una expresión de nuevas asimetrías en el conjunto de brechas sociales existentes. Éstas incluyen las brechas entre el Norte y el Sur, los ricos y los pobres, los hombres y las mujeres, las poblaciones urbanas y rurales, aquellos que tienen acceso a la información y aquellos que carecen del mismo. Dichas disparidades pueden verse no sólo entre las diferentes culturas, sino también dentro de las fronteras nacionales. (Declaración, 2003, p. 7).

Propugna por garantizar el acceso universal, en virtud de su condición fundamental para el desarrollo humano. Reinvindica, el derecho del individuo a la libertad de opinión y expresión, así como su derecho a recibir informaciones y difundirlas por cualquier medio. Finalmente destaca la participación fundamental del ciudadano en la construcción de una sociedad democrática.

Es necesario incorporar una perspectiva democrática en las sociedades de la información y la comunicación en las que la información es crucial para los ciudadanos y las ciudadanas, a fin de poder adoptar decisiones basándose en el conocimiento de las alternativas y las oportunidades. La información y la comunicación son los cimientos de la transparencia, el debate y la adopción de decisiones. (Ibid: 21).

A 26 años del Informe, esa transformación del público "espectador y testigo pasivo" en un público "ciudadano y participativo" se advierte cada día y se materializa de forma contundente en los registros estadísticos de las encuestas y en las movilizaciones estimuladas por la sociedad civil.

Opinión pública y transformación del espacio público en América Latina: • 337 del informe MacBride a la red Indymedia 
Bibliografía

Aguilar, L. F. (1987, octubre/diciembre). Una reconstrucción del concepto de opinión pública, Revista Mexicana de Ciencias Politicas y Sociales, No. 130.

Castells, M. (1999). La era de la información: El poder de la identidad (Vol. II., Cap. 6). México: Siglo XXI editores.

Davison, P. W. (1968). Enciclopedia de las Ciencias Sociales (Vol. Opinión Pública).

Sociedad Civil de la CMSI. (2003). Construir sociedades de la información que atiendan a las necesidades humanas, Declaración de la sociedad civil en la Cumbre Mundial sobre la Sociedad de la Información.

Habermas, J. (1981). Historia y critica de la opinión pública: La transformación estructural de la vida pública (1 ${ }^{a}$. ed. en alemán). Barcelona, España: Gustavo Gilli.

Katz, Elihú \& Lazarsfeld. (1979). La influencia personal. Barcelona, España: Hispano Europea.

Keane, J. (1997, enero/abril). Tranformaciones estructurales de la esfera pública, Estudios Sociológicos.

Lazarsfeld, P., Berelson, B. \& Gauset, H. (1962). El pueblo elige: Estudio del proceso de formación del voto durante una campaña presidencial (1 ${ }^{a}$. ed). Buenos Aires, Argentina: Editorial Paidós.

Luhmann, N. \& Rafaelle, G. de. (1993). Teoría de la sociedad. México: Universidad de Guadalajara/UIA/ITESO.

MacBride, S., et al. (1980). Un solo mundo, voces múltiples: Comunicación e información en nuestro tiempo. México: UNESCO/FCE.

Marques de Melo, J. Comunicación y poder en América Latina. Las ideas de MacBride en el ocaso de la guerra fría, TELOS, Num. 33.

McCombs, M. \& Shaw, D. (1972, summer). The Agenda-setting Function of Mass Media, Public opinion quarterly, No. 36.

Price, V. (1994). Opinión Pública. México: Universidad de Guadalajara/DOPSA/PEAC.

Ramonet, I. (2002, agosto). Entrevista con Ignacio Ramonet, Granma.

Sartori, G. (1992). Elementos de teoría politica. Madrid, España: Alianza Universidad Textos.

Sartori, G. (1998). Homo Videns: La sociedad teledirigida. México: Taurus.

Thompson, J. B. (1998). Los media y la modernidad. España: Paidós Comunicación.

Wolton, D. (1992). La comunicación política: construcción de un modelo, El Nuevo Espacio Público. España: Ed. Gedisa.

Wright, C. (1978). La elite del poder. México: Fondo de Cultura Económica. 